\title{
Community Capacity Building: The Role of Design in Entrepreneurship
}

\author{
Sangeeta Karmokar* \\ Auckland University of Technology
}

\begin{abstract}
Academic entrepreneurship refers to efforts undertaken by universities to promote commercialization, start-ups, technology transfer and university spin offs. A growing trend among tertiary students is to consider not only traditional ventures and new product initiatives but also expand initativesto include social ventures that serve social needs. This paper builds upon the emerging interest and explores ways to connect academic entrepreneurship to external communities through design methods. We use design as a core component of all activities and observe how these activities foster ethnic entrepreneurship. The knowledge and application of design methods is transferred from product development to entrepreneurial capacitybuilding in the ethnic community. Ethnic entrepreneurship is a challenging process of identifying opportunities in a new market, and undertaking innovative projects. Small communities and minority groups often feel left out either because they come from a different background and culture, or because they are unfamiliar with entrepreneurial approaches, and lack the necessary networks that are required to become entrepreneurs. This paper presents a pilot study in which we have addressed key entrepreneurial needs of a selected community, through a series of capacity-building workshops based on design methods.

Keywords: academic entrepreneurship, design methods, ethnic entrepreneurship, capacity building.
\end{abstract}

\section{Introduction}

Academic entrepreneurship has grown drastically over time due to rapid technology growth and awareness of innovation opportunities (Lockett, Wright, \& Wild, 2014). There has been an increase in university licensing, patenting, start-ups, university spin offs and other forms of commercialization (Link, Siegel, \& Wright, 2015). The purpose of academic entrepreneurship has shifted from just providing knowledge to aiding with social improvements in the wider community (Siegel \& Wright, 2015). This perspective of entrepreneurship has broadened the ecosystem to reflect wider social and economic benefits to diverse communities. There is relatively less direct discussion on how design can be used to support academic entrepreneurship (Simeone, 2014). Design has a unique set of abilities to connect and communicate with users at a very early stage of an entrepreneurial journey. Simeone (2014) claim that because of this uniqueness, design should be more proactively used in entrepreneurial settings. This case study is on design oriented activities towards entrepreneurial thinking that includes the product innovation, prototype development, feasibility analyses and market validation. This has contributed interesting insights for design and academic entrepreneurship. The use of design approaches is a rising phenomenon especially in social entrepreneurship. Design has been used extensively especially for connecting with external stakeholders and to activate the process of value creation (Simeone, 2014). We discuss the use of design in building entrepreneurial capacity among ethnic communities in New Zealand.

In recent decades in the industrialised world, especially in metropolitan areas, there has been a large influx of people from different socio-cultural or ethnic origins (Ramadani, Rexhepi, Gërguri-Rashiti, Ibraimi, \& Dana, 2014; Vries, Hamilton, \& Voges, 2015). Diversity has resulted in a wide variation of personal strengths such as language skills, social, cultural and international connections that can be channeled into entrepreneurship and transferable to local economies (Gunay \& Aydin, 2015).

New product innovation and entrepreneurial activities are common interests identified in diverse ethnic communities. Skilled migrants and entrepreneurial categories have different cultural beliefs and language skills, perspectives and ideas, that can help grow or start-up new businesses (Karmokar, 2016). Majority of ethnic entrepreneurs operate in the services sector with small start-up capital and manage to generate a small income (Ramadani et al., 2014). Generally, these communities have lower levels of education and tend to use informal sources to support their business. Ethnic entrepreneurs face various barriers but the most important challenge in capacity building is to understand the importance of sociocultural backgrounds of diverse communities and design a capacity-building framework that delivers value to both the minority communities and the economy.

The following sections present an overview of academic entrepreneurship and its emerging role, the use of design in innovation and building entrepreneurial skills through a set of workshops and hands-on

${ }^{*}$ Corresponding author: Dr. Karmokar is Senior Lecturer at the School of Future Environments, Faculty of Design and Creative Technologies. E-mail; sangeeta.karmokar@aut.ac.nz 
activities. The case study presented below was funded by The Office of Ethnic Communities of New Zealand.

\section{Literature Review}

Academic Entrepreneurship and the Changing Environment

The evolution of academic entrepreneurship is viewed in the context of the debate regarding the nature and purpose of universities, which has a long history (Martin, 2012; Vesperi, Reina, \& Gentile, 2015). On the one hand is the view that the purpose of universities is for education's sake and that research conducted at universities should be basic in nature for promoting knowledge. On the other hand, universities are viewed from a more practical perspective involving the improvement in the society and the community (Siegel \& Wright, 2015; Tarman, 2017; Tarman \& Chigisheva, 2017; Yigit, 2018).

Generally, many academics engaged in teaching entrepreneurship have traditional norms, standards and values unlike many modern practicing entrepreneurs. However, these traditional approaches have largely not considered all dimensions of the new entrepreneurial eco-system, which has broadened out the rationale to include the wider social and economic benefits of academic entrepreneurship (Siegel \& Wright, 2015). Table 1 summarises these differences:

Table 1.

Traditional and Emerging Perspectives on Academic Entrepreneurship

\begin{tabular}{cll} 
Theme & \multicolumn{1}{c}{ Traditional Perspective } & \multicolumn{1}{c}{ Emerging Perspective } \\
\hline Why & $\begin{array}{l}\text { To generate direct financial } \\
\text { returns }\end{array}$ & $\begin{array}{l}\text { To provide a wider social and economic benefit to } \\
\text { the university ecosystem }\end{array}$ \\
What & $\begin{array}{l}\text { Academic Spin-offs; licensing; } \\
\text { patents }\end{array}$ & $\begin{array}{l}\text { Student and Alumni start-ups; Entrepreneurially- } \\
\text { equipped students; Job creation in the local region } \\
\text { or state }\end{array}$ \\
How & $\begin{array}{l}\text { Academic faculty and post- } \\
\text { doctoral students }\end{array}$ & $\begin{array}{l}\text { Students; Alumni; on-campus industry } \\
\text { collaborations; surrogate entrepreneurs }\end{array}$ \\
& Science parks & $\begin{array}{l}\text { Accelerators; Entrepreneurship garages; student } \\
\text { business plan competitions; collaborative networks } \\
\text { with industry and alumni; employee mobility; } \\
\text { public-private 'incubators' }\end{array}$
\end{tabular}

Source: (Siegel \& Wright, 2015)

Table 1 shows the shift in academic entrepreneurial activities. Understanding of this shift in practice provides a new direction to both academics and practitioners and its implications for the wider community. Academic entrepreneurship has evolved, there has been a rise in scholarly interest in academic entrepreneurship in the social sciences (e.g., economics, sociology, psychology, and political science) and several fields of social issues (Siegel \& Wright, 2015). The shift in focus of entrepreneurial activities is affecting the way academics connect with students, industry and external communities. With the increased activities in social entrepreneurship and public-private entrepreneurship, we see stronger connections with industry and communities.

Traditional entrepreneurship (defined as mode-1 knowledge production) is internally initiated in academic contexts by researchers and carried out within disciplinary borders. On the contrary, Mode-2 knowledge production is context driven, and involves multi-disciplinary teams brought together to respond to real-world problems and challenges (Siegel \& Wright, 2015). According to Kingma (2011), the notion of academic entrepreneurship denies the importance of processes such as marketability, entrepreneurial dynamics, profit-driven economics, but claims that the very process of engagement with the community is a key element for creating value. The emerging direction does not diminish the importance of traditional entrepreneurship but takes it to a new level with added values. Entrepreneurship is no longer tied to the monetary outcomes but also oriented towards societal value (Kingma, 2011). Use of design approach fosters a way for academia to adopt entrepreneurial approaches and reflects upon open issues potentially related to some of these approaches.

\section{Role of Design in building Innovation and Entrepreneurship}

Emerging technological developments have changed the relationship between people and technology. A broader issue is whether design means the same thing for different conceptions of the "user": 
can we design experiences for different types of users? While researchers have attempted to address these changes (Blythe, Monk, Overbeeke, \& Wright, 2018; Sas \& Dix, 2009), usability has remained as the central concern. Since designing and evaluating the user experience is a relatively new area in human centered interface design, not many processes or methods are available. Design thinking may help overcome this limitation. It is a discipline that uses the designer's creativity and sensibility to match people's needs with what is technologically feasible and what a viable business strategy can convert into customer value and market opportunity. Understanding emotional and cognitive experiences of the users is central to the design thinking proces.

Many practitioners regard a design-thinking concept as a measure to generate innovative and creative strategies. The creative thinking process of designers is believed to stimulate out-of-the-box thinking and contribute to innovation in an organization (Tarman, 2016). The design approach has stimulated innovation in many areas by making new products and technologies aesthetically attractive and therefore more desirable to consumers. The design approach as a 'thinking and doing' process is originally from the product development domain, but the approach can be applied to multiple domains. Many current applications of design thinking follow this path and have led to promising and challenging propositions in social design and business (Simeone, 2014; Karpov, 2017).

Companies encourage designers to create innovative ideas that better meet consumers' needs and desires, which add value to the business. A broad design thinking framework is shown below (Figure 1). This is one of the most used framework in the creative industries.

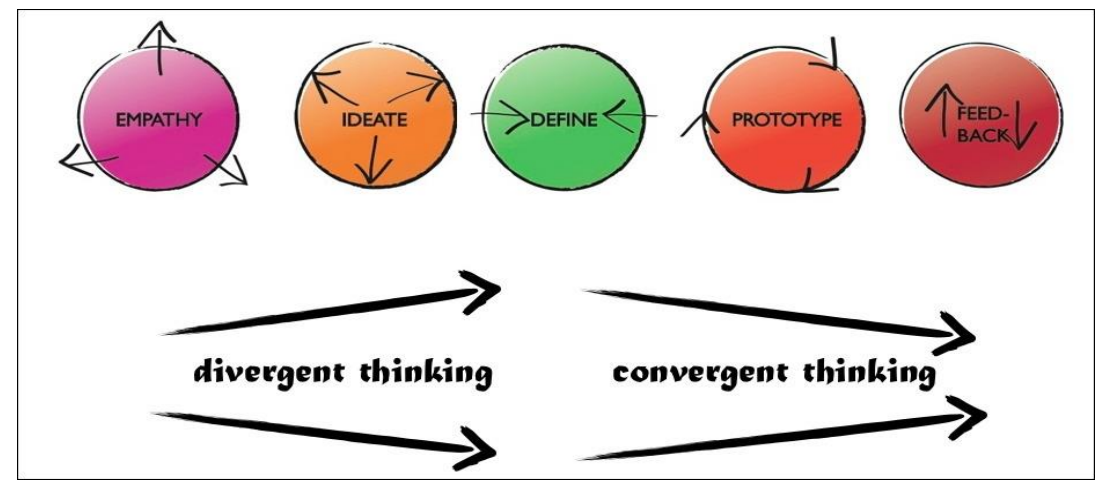

Figure 1. Design Thinking Framework (Brown \& Wyatt, 2010)

Various methods and tools (such as the lotus blossom, personas and six thinking hats) are used to guide the design thinking process to create an effective solution. These tools and techniques are useful for recognizing patterns, constructing ideas that have emotional meaning as well as being functional, and expressing users' values in media other than words or symbols. Design methods plays a significant role in connecting academic entrepreneurship with external communities. It sustains interaction through iterative processes of empathy mapping, prototyping, connecting with users, and external stakeholders in co-design.

There are few reported discussions on how design can be used or adopted for fostering entrepreneurial activities (Simeone, 2014). Design has a unique set of abilities to communicate and as a novel problem-solving methodology well suited to the often-cited challenges business organizations face in encouraging innovation and growth. The use of design as a thought process might improve innovation outcomes in the early stages of new ventures used in entrepreneurial settings (Liedtka, 2014). However, the Design Management Institute (DMI) has proposed some criteria which are used to measure the contribution of design to business:

Table 2.

Proposed Criteria by Design Management Institute

1. Purchase influence/innovation

2. Enable strategy/new markets

3. Enable product and service emotion

4. Reputation/awareness/brand value

5. Time to market/process improvement
6. Cost savings/ROI

7. Customer satisfaction

8. Developing communities of customers

9. Good design is good for all/triple bottom line

Source: (Best, 2010) 
The above criteria are mostly oriented towards studying how design can foster and support economic and social ventures. Design offers the opportunity to translate ideas and concepts into viable business ventures through a structured process and selected appropriate methods. The value generated in design process takes many forms such as the generation of knowledge, collaborative startups, spin offs, wealth creation, and addressing complex social issues.

While the design process keeps users as a focal point, building an engagement with external stakeholders is crucial. One of the success factors of modern entrepreneurial ventures, also depends upon how they cross the traditional borders of entrepreneurship and collaborate with many external stakeholders.

In this paper, design is used as a core component of all the activities as a way to foster networks and entrepreneurship through the active involvement of community members and other support organisations.

\section{Pilot study: Building Entrepreneurship Capabilities in New Zealand Contextual Background}

Ethnic entrepreneurship is growing rapidly in Western countries (Schiller \& Cagiar, 2013). There is evidence around the world that reports many success stories of how ethnic businesses transform the host country's economy (Liu, Miller, \& Wang, 2014). Ethnic enterprises contribute positively in building stronger communities and local development. They form an important force in transforming the economic, social and cultural landscape of a country. Due to differences in their language, culture, environment and social norms most of the ethnic groups aim for self-employment (Verheijen, Nguyen, \& Chin, 2014). The trend is regarded as ethnic entrepreneurship. Ethnic entrepreneurship is a process of identifying opportunities in the market, undertaking innovative, activities by individuals who are not members of the majority population in a given country, to ensure prosperity for themselves, family and society (Ramadani et al., 2014).

Ethnic entrepreneurship is well-recognised and valued by many countries across the globe. There are many barriers faced by ethnic communities such as lack of education, lack of management skills, difference in social and cultural values, restrictions on access to formal business networks, outdated knowledge and skills, lack of self-confidence in a new environment, fear of failure and lack of access to financial resources (Verheijen et al., 2014). Many local and regional governments have added programmes and initiatives to promote ethnic entrepreneurship, such as Migrant Entrepreneurship Program by ATTED (Auckland Tourism, Events and Economic Development), Diversity Entrepreneur Support by MBIE (Ministry of Innovation and Employment) and Live Your Dream by The office of Ethnic Community (http://ethniccommunities.govt.nz/).

\section{Research Methods}

This research builds on an ethnographic study by Simeone (2014) who presented how academics can engage with external communities to enhance entrepreneurship capacity. Based on the literature in this field, and the success of design methods, we combined design approaches into a series of three workshops that are described below. Each workshop consisted of a number of design methods to encourage creativity, critical thinking and self-reflections. These attributes have been found to aid in active entrepreneurial behaviour (Kingma, 2011).

\section{Design Methods for Entrepreneurial Capability Building}

There are some successful frameworks and methods used for capability building. The success of a capability building programme depends upon an ability to establish a rapport with the community. The author's 'Live your dream' programme is in response to the New Zealand Government's encouragement to see its investments in University teaching and research to deliver social benefits to all New Zealanders.

With the support of The Office of Ethnic Communities (New Zealand Government), 'Live your dream' programme and workshop series were held from February to May in 2017 in Auckland, New Zealand. It is a programme to inspire and raise awareness of how to go about finding opportunities and developing concepts in a new changing market place. The programme encouraged people to develop selfawareness and draw on their creative potential with a specific focus on their contribution to a more diverse New Zealand workforce and society.

Design methods were the core component of all activities in the workshops. Some of the methods included confidene buiding canvas, empathy mapping, lotus blossom techniques and persona. The workshops included hands-on activities in creative problem solving, to identify opportunities, and to put in action new techniques for creative thinking, collaboration, leadership, and entrepreneurship. Participants were encouraged to start their own enterprise and briefed on the opportunities available for such enterprises, keeping in mind the resources and technical feasibility analysis required. 


\section{Analysis/Study}

This case study presents and evaluates the series of workshops conducted, namely: Creative Confidence workshop, Entrepreneurial thinking and Logic workshop held in Auckland, New Zealand. A combined total of 98 people attended for 3-hour workshops. The workshops were facilitated by experts in human-centered design principles and digital product innovation. The facilitators had a wealth of experience in design, entrepreneurship and visual thinking exercises, which enriched the participant's knowledge.

The aims of the Creative Confidence workshop were to encourage participants to develop selfawareness and build their creative contributions. We used confidence building canvas to The design methods used to build the creative confidence. Below (Figure 2) is the canvas participants used for understanding their strengths and goals.

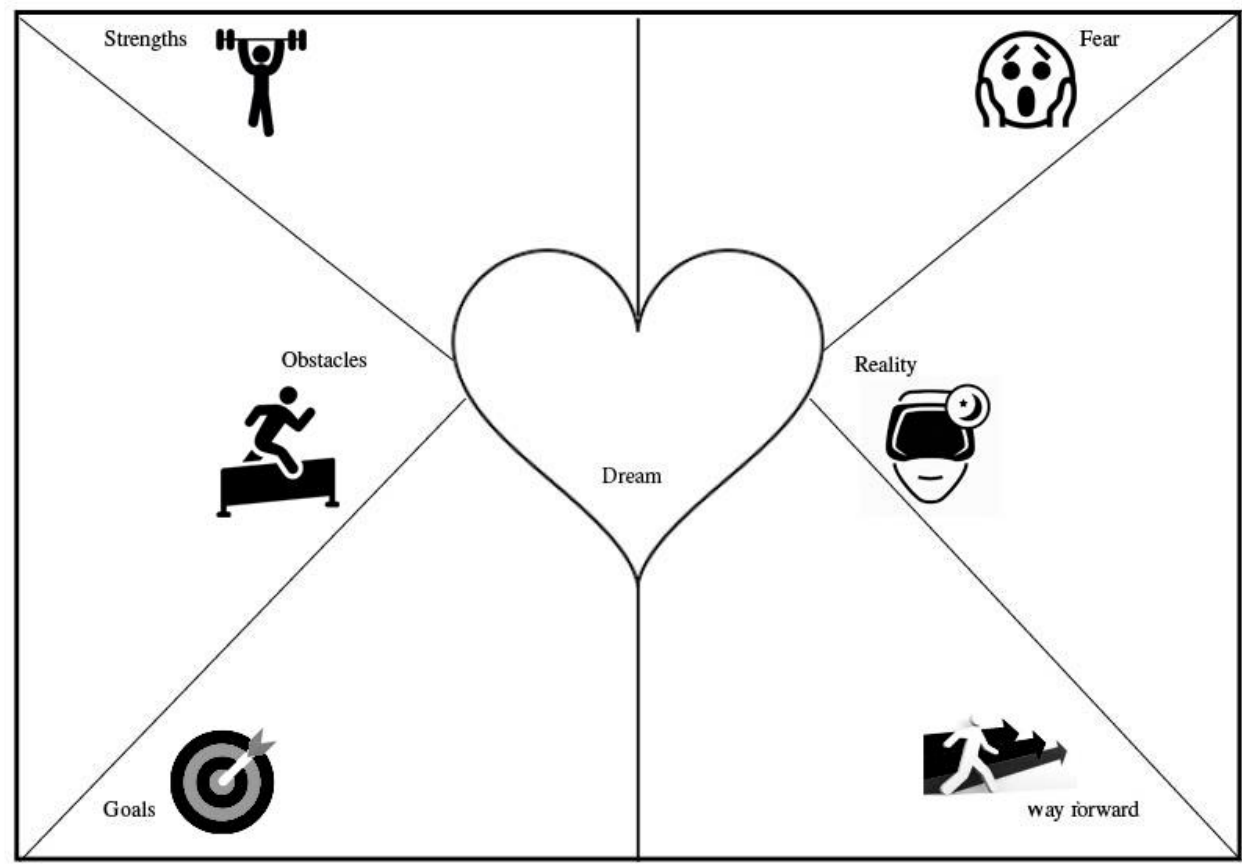

Figure 2. Creative Confidence Canvas

The Entrepreneurial Logic workshop supported participants to formulate entrepreneurial plans. The idea was that participants would be better prepared for their future by planning around their strengths. Design methods used for identifying the opportunities was lotus blossom.

Graphic Organiser - Lotus Diagram

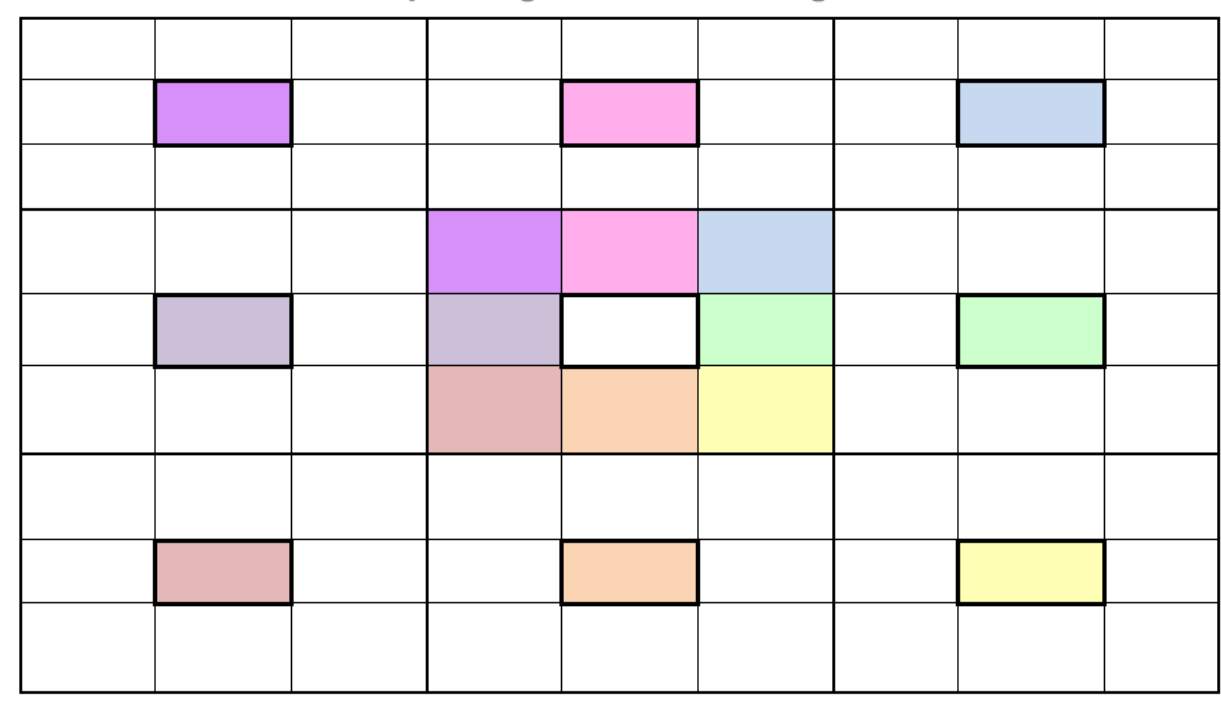

Figure 3. Lotus Blossom 
Lotus blossom (Figure 3) is one of the structured form of brainstorming used in design workshops. To further undestanding the users and their requiremetns, we used empathy mapping (Figure 4).

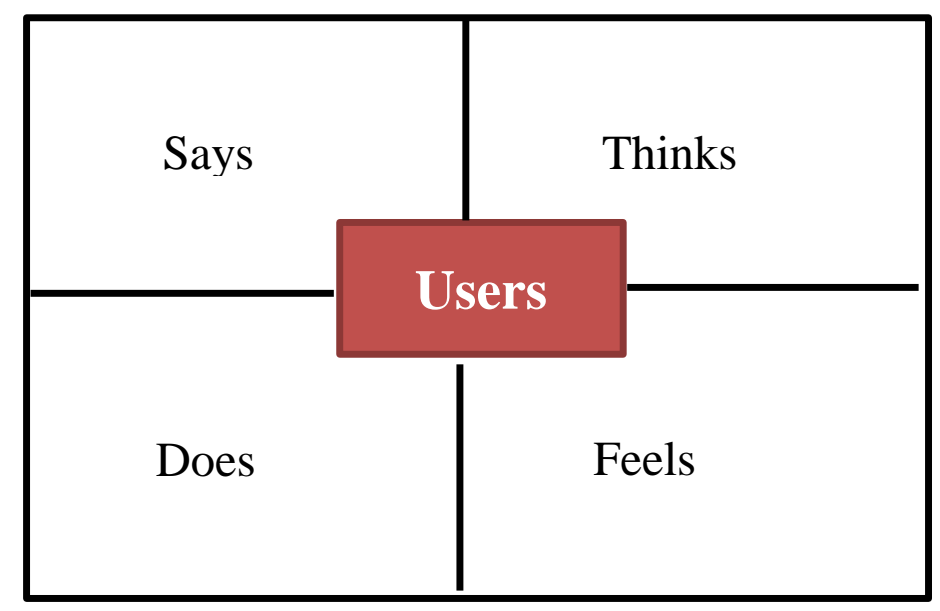

Figure 4. Emapthy Mapping Canvas

The workshops presented key design methods, and were scaffold to progress towards building entrepreneurial skills. We used De Bono's six thinking hats (Figure 5) for refining the ideas.
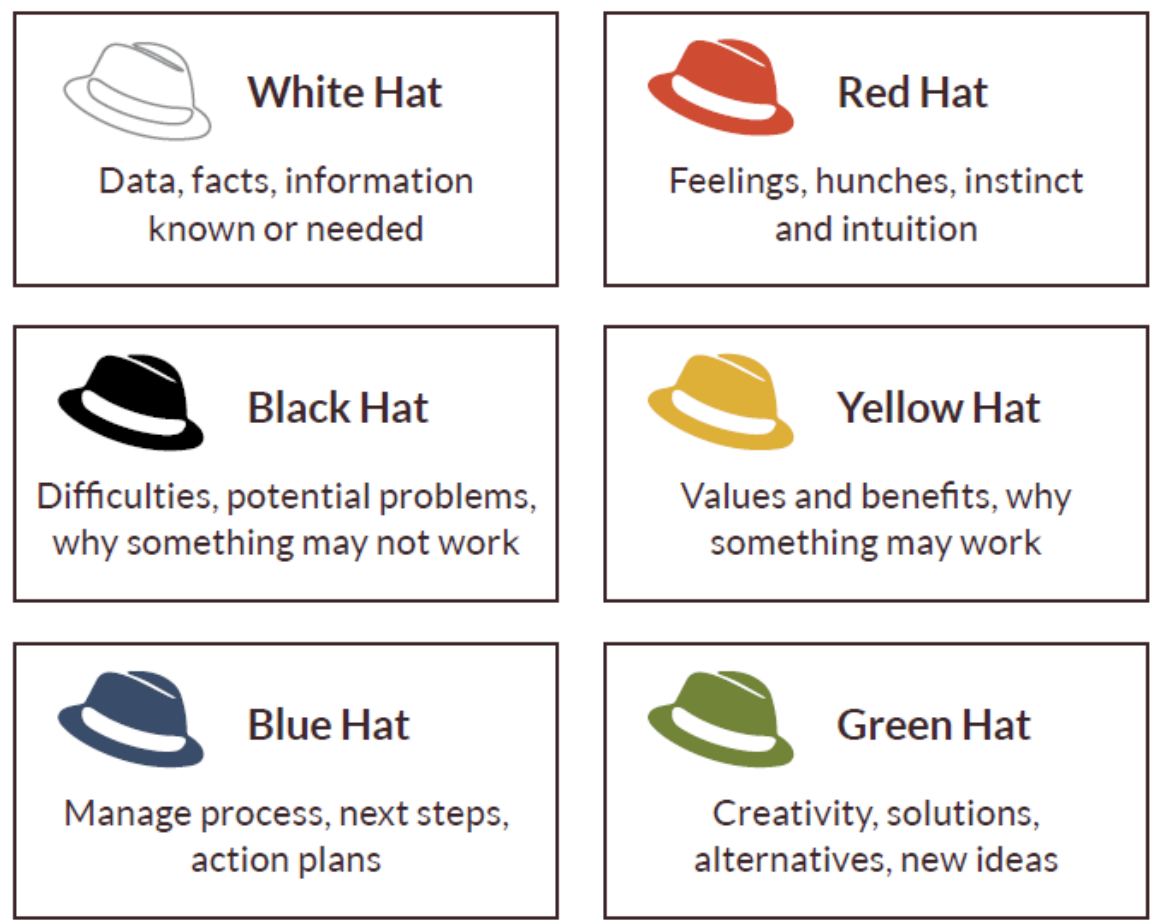

Figure 5. De Bono's Six Thinking Hats 
Figure 6 below shows that the diversity of participants from the two workshops. A majority of the participants are from India and Sri Lanka.

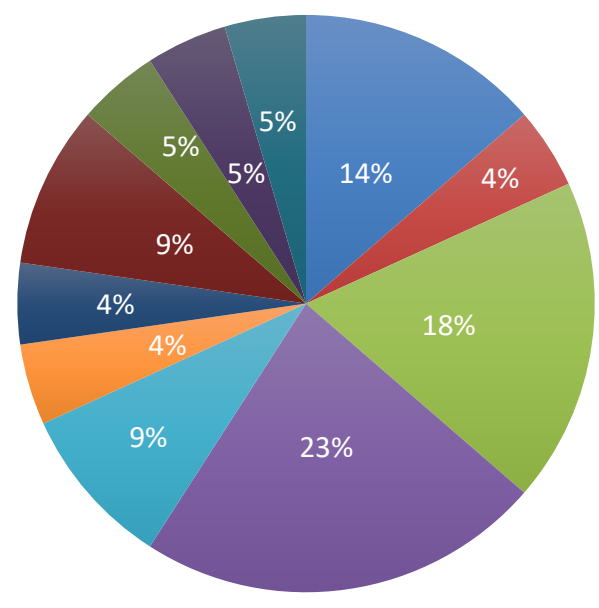

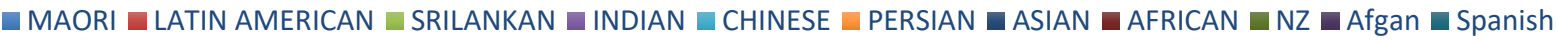

Figure 6. Ethnic Diversity of the Participants

It was a good mix of cultural diversity and social values represented in the groups. This resulted in a few challenges as it was not easy to understand and relate immediately to a person's view point at times. However, the diversity provided some opportunities to understand matters from another point of view, and frame concepts from a new angle. These led to good discussions, and interactions between members of the group.

The design process started from building creative confidence to various entrepreneurial development. The design approach proven to be stimulating innovation among participants and helped to build emotional connectivity. Some of the design methods used in these workshops were, confidence building canvas, lotus blossom, empathy mapping and six thinking hats

\section{Results and Discussion}

Survey research was used as the research method to gain feedback and evaluate the workshops. The survey was in the form of print and online (using Survey Monkey online software) surveys containing structured close-ended questions (i.e. multiple choice and Likert scale) and open-ended questions. The survey solicited information on participants' age, gender, whether participants' expectations were met, helpfulness of the workshop to think in new ways, usefulness of the workshops, the most and the least relevant aspects of the workshop, ability to put into practice learning from the workshops and topics of interest for future workshops.

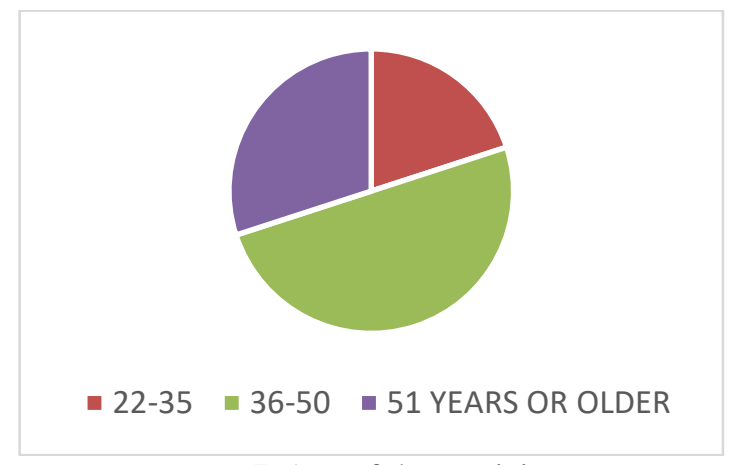

Figure 7. Age of the Participants

According to Figure 7, almost half (44\%) of the respondents were people aged 35-55 years, and with the majority as females. According to our study, in ethnic communities age is not an issue to be an entrepreneur. Participants saw entrepreneurship as an opportunity to explore their contributions and to stay employed in an immigrant country. It was interesting to see more female participants than male, as historically men have dominated the entrepreneurial world (Verheijen et al., 2014). Women have broken out of traditional gender roles to get into business and be independent. Various research studies show that 
women start their own businesses because they want independence, control and that they are assured that their businesses will deliver income and personal satisfaction (Ewere, Adu, \& Ibrahim3, 2015).

Almost all of the respondents were not looking for employment (72\%) as more than half (67\%) were fully employed. In spite of being full time employed many participants had a willingness to explore their skills to see if they could create or build an idea. Literature indicates that the rate of unemployment, marriage, family, gender, length of time in a country and lack of education are some of the variables that can direct individuals towards entrepreneurial journeys (Vries et al., 2015).

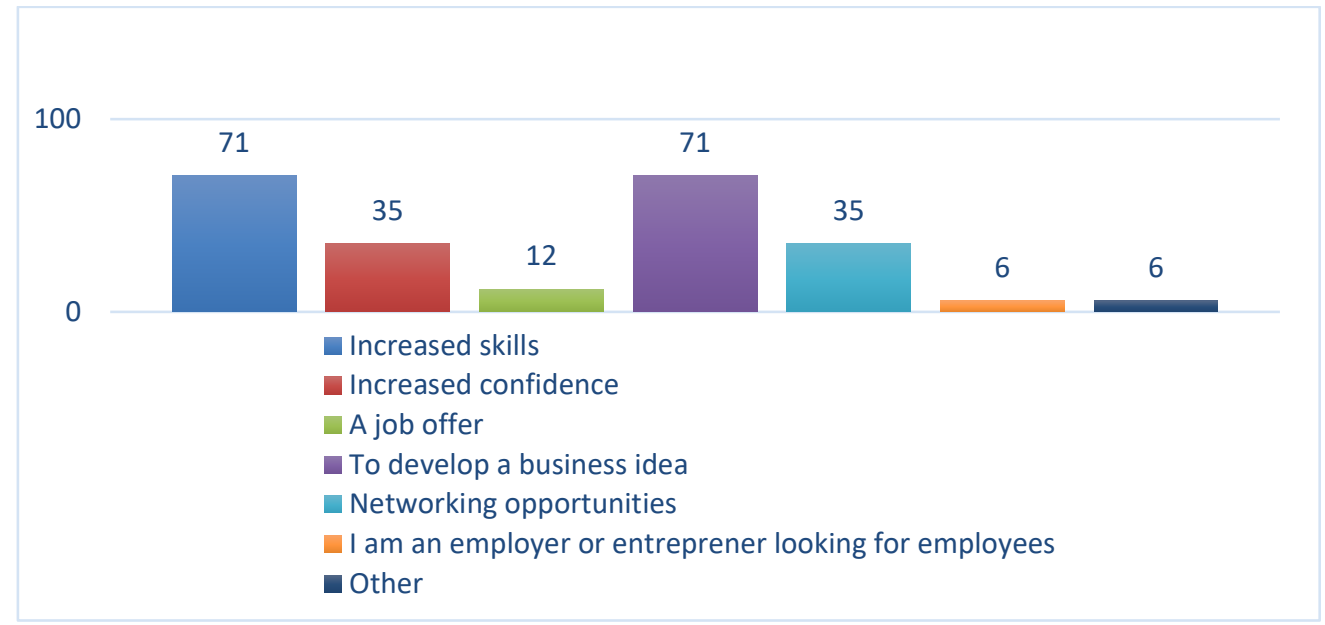

Figure 8: Participants Expectations from the Workshops

However, even if almost all were fully employed, participants' expectations from the workshops were the following: to develop a business idea for a start-up (71\%); to increase networks (35\%); to increase skills $(71 \%)$; and to increase confidence (35\%). There were also some employers or entrepreneurs who attended the workshops and looked for recruitment. Some participants looked for networks.

The workshop was rated highly positive with more than half $(85 \%)$ who strongly agreed and more than a quarter $(15 \%)$ who agreed it met their expectation. Likewise, nearly half of the participants strongly agreed that the workshop helped them to learn or gave them the ability to think in new ways.

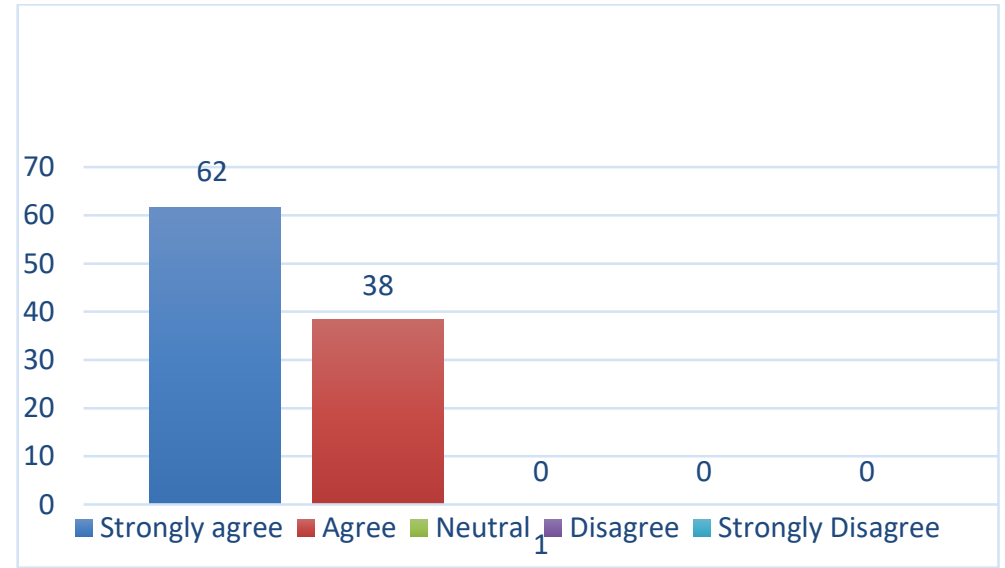

Figure 9. Encourage New Ways of Thinking

To encourage new way of thinking, few creative methods such as brainstorming and assumption mapping were used. According to the survey, 62\% of the participants strongly agreed that workshop provided them with the ability to think in new ways. Creative thinking of ethnic community is influenced by various factors such as their geographic origin, cultural and religious values, language, personal connection and intellectual experience. Lotus blossom method is a more structured and way to encourage a new way of thinking that aligns and integrates with the new environment. 


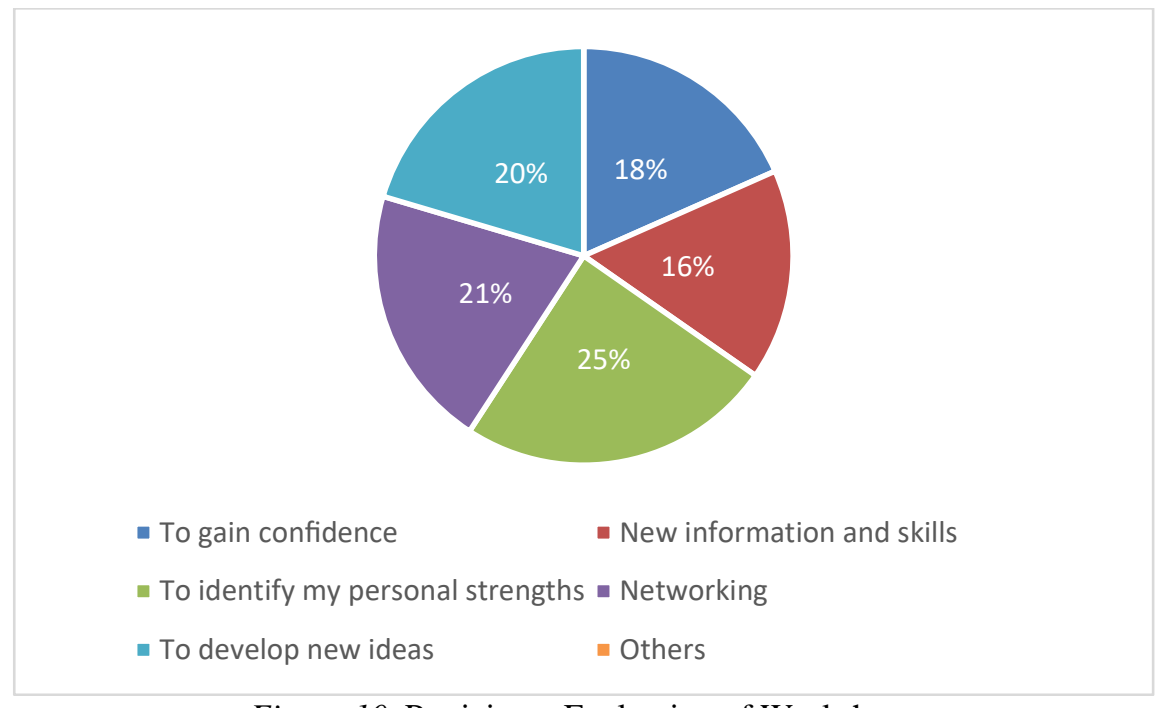

Figure 10. Participant Evaluation of Workshops

Participants rated the workshop's top benefits as: to gain confidence, new information and skills, to identify their personal strengths, networking and to develop new ideas. The primary benefit derived from the workshop by the participants were to identify personal strength, develop new ideas and networking.

The following factors were identified by the participants of the workshops as the most relevant aspects:

Table 3.

Participant Evaluation of the Workshops

\begin{tabular}{ll}
\hline Networking & Personal ability awareness \\
Identify personal fear & Self-awareness \\
$\begin{array}{l}\text { Internal reflection using SWOT } \\
\text { analysis }\end{array}$ & Getting started with my idea \\
Decide on point of difference & $\begin{array}{l}\text { Fleshing out business ideas from } \\
\text { opportunities } \\
\text { Identifying the need and passion }\end{array}$ \\
Getting business models right & Brainstorming \\
\hline
\end{tabular}

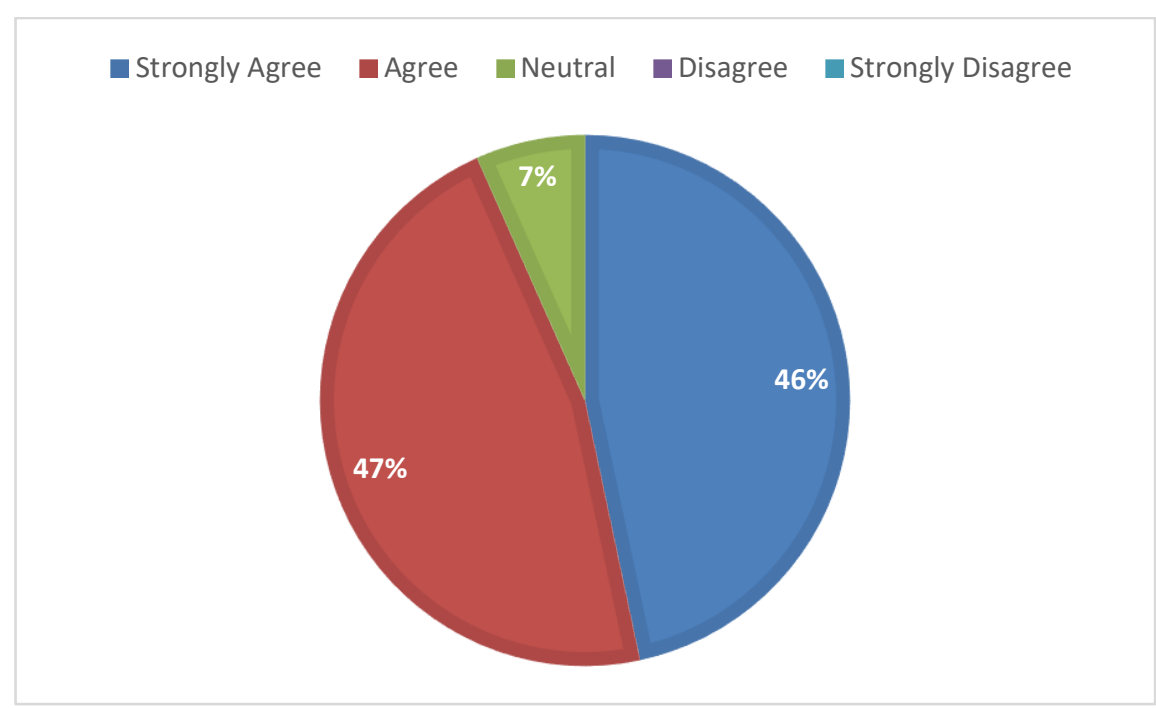

Figure 11. Workshop Knowledge Applying to Practice

The majority strongly (Figure 11) agreed that they would be able to put into practice what they learned from the workshop, while the rest of the participants agreed to put their knowledge into practice. 
This implies that the participants have not only gained knowledge and skills but also confidence in using them.

\section{Discussion}

In this study, a series of workshops were planned and implemented in order to build capabilities in design and entrepreneurship among ethnic communities in Auckland, New Zealand in 2017. The authors have observed that using design methods for capability building in entrepreneurship provides a new way of looking at ethnic resources. We have identified and shared multiple strategies that they can implement by using design methods to navigate through their challenges.

Overall, these workshops were well received, and established a demand for more design workshops. The workshops provided skills in problem solving, design process, increased confidence in planning for start-ups, development of business ideas, and networking. Knowledge about gaining opportunities was an important lesson that the participants received. The next step will be taking their ideas into market validation and protyping stage.

Although their entrepreneurship interests were quite diverse, these ethnic entrepreneurs revealed similar strengths and characteristics such as optimism, resilience, determination and commitment. Participants demonstrated a positive attitude of will power, commitment and openness to accepting new directions, which are key factors in their future entrepreneurial endeavors. This study shows that despite some challenges, it is possible to enhance new immigrants' confidence to search for opportunities and develop new products that can lead to new ventures. They learnt some simple new methods of visualisation that enabled better discussions about their new product concept or new business. They learnt that it is okay to fail at early stages of concept development, and to learn what is wrong by critiquing ideas together, and to handle the critiques better.

The collaborative atmosphere of the workshops encouraged participants to ask a lot of questions about the others' product designs and business ideas - such as: "how will this work? Who will use it? Where can it be used? Why do people want it? What are the benefits? Who are the stakeholders?" and so on. The discussion was part of the workshop and participants were encourage to think creatively. Designing a product or service at the end of these workshops was participants choice but they were provided with tools and methods to think in an entrepreneurial way.

The study shows that the application of user-design methods motivated students to build empathy and understand users' needs. The projects outputs and feedback confirmed that design based hands-on activities could engage participants and help them improve their problem-solving behaviour and build creative confidence.

Using a practical case study, this paper provides a design framework in which academic entrepreneurship can be applied in building entrepreneurial capability in an immigrant community. Most of the existing academic entrepreneurial education is based upon the characteristics of particular universities and their faculty. However, with the Mode-2 framework the approach of academic entrepreneur is more focused towards the process of engagement with the community and that is a key element for creating value. The emerging direction does not diminish the importance of traditional entrepreneurship, but takes it to a new level with added value. This paper demonstrates how we can encourage entrepreneurial behaviour among ethnic communities and ways of using design to engage with hands-on activities and collaborations. We can build capabilities by integrating academic entrepreneurship concepts with elements of design. Evidence from the case study shows an effective relationship between academic entrepreneurship and design. Research is needed on the benefits and challenges in incentivising academics to move towards more integrative processes (Siegel \& Wright, 2015). There are challenges when applying academic knowledge into community environments especially with diverse participants. Few of the challenges are discussed in the next section.

\section{Challenges}

Using design techniques to build entrepreneurial capabilities was novel, rewarding and challenging. Relating some of these methods to the grass root level and using it effectively in such a diverse group of participants was a new experience. There was always a conscious effort to make sure that participants felt included in all the activities. Methods such as brainstorming and empathy mapping have been used in other contexts, but relating it to their social and cultural values to identify themselves and selfreflection was fascinating.

The confidence building canvas method proved challenging, due to the fact that some people are not used to seeing weakness and drawbacks in themselves or their surroundings. Self-reflection and selfcritiques was something many of them had never done. It was emotionally uncomfortable to see their own weaknesses and acknowledge them, in order to move forward. This was part of the confidence building workshop. In the initial stage of the project, the challenge for the facilitator to recognise the historic and social complexities of the participants and adopt new ways to move beyond those beliefs was a difficult 
task. Design methods such as empathy mapping helped to overcome their fear of failure and exposure of weaknesses, which are not natural behaviours for this ethnic community. The reasons behind it may be, the social expectations and the family beliefs they are raised with. To address this issue, one of the actions that we adopted was working and presenting as a group rather than individual presentation. This provided a collective voice that is more acceptable and flexible. These methods helped them speak up and voice their opinions better.

Overall, participants appreciated the workshop with comments such as:

"Never realised what we can achieve in just one workshop, amazing.

"We learnt many business models. We say that there are many ways to solve a problem and not limited to one. You showed us interesting tools and how to see the problems with different perspectives, thank you."
"When we started off, we didn't know what we were getting, at start, I felt 'can't I think better than this, as I was stuck in the four walls of thinking.' Now I walk out with a different way of thinking and new ideas that I can expand on."

"You never write down your strengths and weaknesses. It is good exercise and very, very helpful."

"It made me think of what I want to achieve instead of just thinking about it, we actually write it down."

"The 'point of difference' is thought provoking. Very good."

"We often don't think about these things but all the time they are affecting us."

\section{Conclusion}

This paper presents a novel approach to encouraging innovating thinking and entrepreneurial behaviour among ethnic communities through design activities. Involving these people directly in handson activities facilitated by the authors, allowed for deep discussions on around how to prepare better for entrepreneurship and innovation, how to network, and how being aware of individual strengths can help.

Using a practical case study, this paper provides a design framework and methods in which academic entrepreneurship can be applied in building entrepreneurial capability in any international or diverse community. The creative thinking process of participants is believed to stimulate out-of-the-box thinking and contribute to innovation in an organization. The design approach has stimulated creative and entrepreneurial thinking and therefore more acceptable in workshop environment.

The workshops attracted a lot of participants' attention. There were some challenges which were solved during the activities as presented above. Overall the design projects enabled collaborations, and helped to build confidence and awareness of how to solve problems. The study revealed that minority groups have strong interests in innovation and entrepreneurship. It also revealed that they possess strengths that are suited to starting up new ventures and developing new products such as a willingness to be flexible, a willingness to learn and adapt to new environments. Workshops such as those presented here can boost their confidence and facilitate their preparedness towards building new products and start-ups. Following such interventions, they can then present better business plans to incubators that already exist, to take them through the next stages of venture growth. The data shows that these preparatory workshops were found to be useful by participants, who showed real improvements in learning and a keenness to apply what they learnt.

\section{Acknowledgments}

We are thankful to The Office of Ethnic Communities, New Zealand for funding this project. Website: http://ethniccommunities.govt.nz/ and to all of the community participants who were engaged in the workshops. 


\section{References}

Best, K. (2010). The fundamentals of design management. UK: AVA Publishing.

Blythe, M. A., Monk, A. F., Overbeeke, K., \& Wright, P. C. (2018). Making sense of experience. In Finology 2 (pp. 315-330). Cham: Springer.

Brown, T., \& Wyatt, J. (2010). Design thinking for social innovation. Stanford Social Innovation Review.

Ewere, A. D., Adu, E. O., \& Ibrahim3, S. I. (2015). Strategies adopted by women entrepreneurs to ensure small business success in the Nkonkobe municipality, Eastern Cape. Journal of Economics, 6(1), $1-7$.

Gunay, R., \& Aydin, H. (2015). The inclinations in studies on multicultural education in Turkey: A content analysis study (2005-2014). Education and Science, 40(178), 1-22.

Karmokar, S. (2016). Managing super diverse women entrepreneurs in Aotearoa New Zealand. Paper presented at the The 11th European Conference on Innovation and Entrepreneurship, Jyväskylä, Finland.

Karpov, A . (2017). Education for Knowledge Society: Learning and Scientific Innovation Environment. Journal of Social Studies Education Research, 8 (3), 201-214. Retrieved from http://dergipark.org.tr/jsser/issue/32449/360852

Kingma, B. (2011). Academic entrepreneurship and community engagement: Scholarship in action and the Syracuse miracle. UK: Edward Elgar Publishing Limited.

Liedtka, J. (2014). Perspective: Linking design thinking with innovation outcomes through cognitive bias reduction. Journal of Product Innovation Management, 32(6), 925-938.

Link, A. N., Siegel, D. S., \& Wright, M. (2015). The Chicago handbook of University technology transfer and academic entrepreneurship. Chicago IL: University of Chicago Press.

Liu, C. Y., Miller, J., \& Wang, Q. (2014). Ethnic enterprises and community development. GeoJournal, 79, 565-576.

Lockett, A., Wright, M., \& Wild, A. (2014). The institutionalization of third stream activities in U.K. higher education: The role of discourse and metrics. British Journal of Managment, 26(1), 78-92.

Martin, B. R. (2012). Are universities and university research under threat? Towards an evolutionary model of university speciation. Cambridge Journal of Economics, 36(3), 543-565.

Ramadani, V., Rexhepi, G., Gërguri-Rashiti, S., Ibraimi, S., \& Dana, L. P. (2014). Ethnic entrepreneurship in Macedonia: The case of Albanian entrepreneurs. International Journal of Entrepreneurship and Small Business, 23(3), 313-334.

Sas, C., \& Dix, A. (2009). Designing for reflection on experience. CHI '91: Proceedings of the Conference on Human Factors in 2009, 4741-4744.

Schiller, N. G., \& Cagiar, A. (2013). Locating migrant pathways of economic emplacement: Thinking beyond the ethnic lens. Ethnicities, 13(4), 495-514.

Siegel, D. S., \& Wright, M. (2015). Academic entrepreneurship: Time for a rethink? British Journal of Management, 26, 4.

Simeone, L. (2014). The potential of design to foster academic entrepreneurship: An ethnographic study of MetaLab at Harvard. Paper presented at the NordDesign, Espoo, FInland.

Tarman, B. (2016). Innovation and education. Research in Social Sciences and Technology, 1(1), 77-97.

Tarman, B. (2017). Editorial: The Future of Social Sciences. Research in Social Sciences and Technology, 2(2). Retrieved from http://ressat.org/index.php/ressat/article/view/329

Tarman, B. \& Chigisheva, O . (2017). Editorial for Special Issue: Transformation of Educational Policy, Theory and Practice in Post-Soviet Social Studies Education. Journal of Social Studies Education Research, 8 (2), i-iv. Retrieved from http://dergipark.gov.tr/jsser/issue/32450/360860

Verheijen, V. W., Nguyen, H., \& Chin, B. (2014). The making of ethnic migrant women entrepreneurs in New Zealand. International Journal of Entrepreneurship and Small Business, 23(3), 296-312.

Vesperi, W., Reina, R., \& Gentile, T. (2015). Academic knowledge vs entrepreneurship: The spin off way. Paper presented at the Europena Conference on Knowledge Management.

Vries, H. P. d., Hamilton, R. T., \& Voges, K. (2015). Antecedents of ethnic minority entrepreneurship in New Zealand: An intergroup comparison. Journal of Small Business Management, 53(1), 95-114.

Yigit, M. (2018). Does higher education change value perceptions?. Journal of Culture and Values in Education, 1(1), 1-8. Retrieved from http://cultureandvalues.org/index.php/JCV/article/view/5 